\title{
Reducing turnover intention: perceived organizational support for frontline employees
}

\author{
Qiang Wang ${ }^{*}$ iD and Chao Wang
}

\author{
*Correspondence: wangqiang@ruc. \\ edu.cn \\ Business School, Renmin University \\ of China, No. 59 Zhongguancun \\ Street, Haidian District, Beijing \\ 100872, China
}

\begin{abstract}
Frontline employees are generally under great pressure, and carry out repetitive and mundane daily tasks, leading to burnout and a high turnover intention among them. To identify ways to reduce this turnover intention, this study examines the effect of perceived organizational support (POS) on burnout and turnover intention in the Chinese context and adds to the literature on frontline employee burnout. Using data from a survey of the frontline employees of a gas station in Beijing, we examine the mediating effects of frontline employee burnout on their POS and turnover intention. This study shows that POS has a significant negative impact on burnout and turnover intention, and that job resources cannot substitute POS.
\end{abstract}

Keywords: Perceived organizational support (POS), Burnout, Retail frontline employees, Job resources, Job demands, Turnover intention

\section{Introduction}

Retail frontline employees act as liaisons between a company and its customers. These employees are generally under great pressure, because they need to fulfill the job demands issued by their colleagues, superiors, and customers. Their work involves helping customers through generally repetitive and mundane daily tasks. This often leads to burnout, especially among employees in the service industry (Cho et al. 2013; Singh et al. 1994; Yagil 2006). Burnout is characterized by emotional exhaustion, depersonalization, and diminished perceptions of job-related abilities (Cordes and Dougherty 1993). Burnout undermines frontline employees' performance and hinders effective customer service (Babakus et al. 1999). Furthermore, employees suffering burnout often consider leaving their job (Babakus et al. 2009; Fogarty et al. 2000). The fact that burnout significantly affects employees--who directly influence service quality and enterprise productivity--has made understanding frontline employee burnout and its consequences an issue of major concern for scholars and managers (Singh 2000).

Many scholars have conducted research to shed light on burnout (Chen and Kao 2012; Han et al. 2016; Pienaar and Willemse 2008). Some studies have identified two major categories of job characteristics linked to burnout, namely job demands and job resources (Podsakoff et al. 2007; Singh 2000). Others have identified personality traits, work environment, and the interaction between them as the main causes of

(c) The Author(s). 2020 Open Access This article is distributed under the terms of the Creative Commons Attribution 4.0 International License (http://creativecommons.org/licenses/by/4.0/), which permits unrestricted use, distribution, and reproduction in any medium, provided you give appropriate credit to the original author(s) and the source, provide a link to the Creative Commons license, and indicate if changes were made. 
burnout--illustrating that environmental factors overpower individual differences (Fogarty et al. 2000). Many scholars use the concept of perceived organizational support to measure and analyze the work environment.

In practice, enterprises also focus on job demands and job resources to alleviate burnout. Some enterprises provide employees with sufficient job resources--such as appropriate training and adequate equipment--while others show concern for their employees by acknowledging their interests, creating a fair environment, and other such means.

This research addresses two gaps in the existing literature in this field. First, in the Chinese context, perceived organizational support (POS) is an important factor that affects the work environment of employees. Organizations care for their employees in several unique ways, including organizing activities, expressing condolences, providing welfare, and more (Dong and Wei 2018). However, previous studies have seldom adequately considered the effects of this support. Therefore, this study addresses this gap in the literature by analyzing the burnout and turnover intention of frontline employees within the Chinese context.

Second, this study also propounds that job resources may play a mediating role in the burnout process. To assess the role of job resources, a mechanism by which the mediating effect (burnout) moderates the interaction between the independent variable (POS) and the dependent variable (turnover intention) is devised in this study. Figure 1 presents the conceptual model guiding this study.

\section{Theory and hypotheses}

\section{The theory of perceived organizational support}

POS theory is an important component of the literature on the relationship between employees and organizations. In the 1980s, American psychologist Robert Eisenberger and his colleagues proposed the concept of POS, which he defined as employees' perceptions and views regarding whether their employing organization pays attention to their contributions and interests (Eisenberger et al. 1986). McMillin (1997) claimed that POS has its origin in the organizational support of employees, which includes moral support, recognition of the importance of employee, and the provision of information, training, equipment, and other tools needed to complete work. Xu et al. (2005) noted that there are two key points to organizational support, namely, an employee's perception of whether their organization observes their contributions, and whether an organization cares about employees' well-being.

While POS and burnout have been extensively studied in the field of human resources, we find that most studies on POS explore its role as a mediator (e.g., Cheng and Yi 2018;

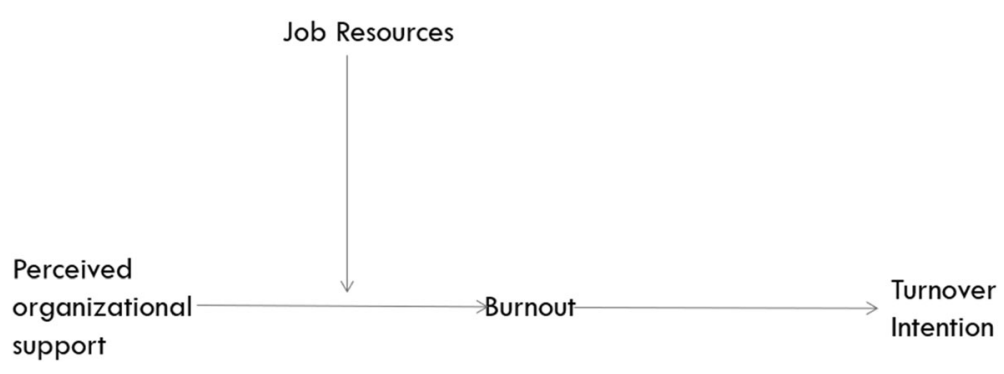

Fig. 1 Research framework 
Palmer et al. 2017), and only a few scholars have considered POS as an independent variable (Wang et al. 2011). Eisenberger et al. (1986) found that employees with high POS are more likely to express a strong sense of belonging and loyalty to an organization. Thus, POS can reduce an employee's turnover intention. A study by Meyer et al. (1993) also showed a significant negative correlation between POS and employees' behaviors of alienation, negative absenteeism, and turnover. Additionally, employees' POS can lead to a reduction in their stress and burnout (Cropanzano et al. 1997).

When employees perceive that they are being supported by their organization, they work harder, and their performance improves. However, if they do not perceive any support, they adopt a passive attitude toward their work and may feel burnout--reducing their efficiency. The main aim of POS is to provide employees with support and encouragement through intangible or tangible methods.

Subsequent studies have demonstrated that support from other individuals and/or organizations can alleviate the consequences of stress within employees (Andrews and Kacmar 2001; Bakker et al. 2014; Sakurai and Jex 2012). Several studies have provided evidence that a workplace environment with significant job stressors induces high levels of employee burnout, which consequently increases employee turnover (Cherniss and Cherniss 1980; Chiang and Jang 2008). Earlier studies have stated that organizational support plays a critical role in increasing positive employee attitudes and behaviors (Cohen and Wills 1985; Day and Bedeian 1991). Researchers have documented that organizational and interpersonal support enables employees to reduce their job stress (Bakker et al. 2014).

According to a study by Tian et al. (2014), the support provided by organizations and leaders helps strengthen the emotional bonds of employees, which is an important determinant of organizational dedication and commitment. Additionally, the same study demonstrated that a supportive work environment plays an important role in reducing various job stressors and improving job performance (Tian et al. 2014). Therefore, POS can reduce or even prevent burnout and turnover intention among employees.

\section{The mediating role of burnout}

Maslach and Jackson (1981) divided burnout into three dimensions, namely emotional exhaustion, depersonalization, and reduced personal accomplishment. Emotional exhaustion occurs when employees expend excessive emotional resources at work and find it difficult to continue fully engaging with their work at the psychological level. A degree of correlation exists between the emotional exhaustion and the depersonalization dimensions. Through depersonalization, employees who are emotionally exhausted view customers as the source of their emotional exhaustion and therefore develop negative, even hostile, feelings toward customers. The third dimension of burnout, reduced personal accomplishment, refers to employees' difficulty in obtaining satisfaction and accomplishment from their work.

There are four main theories on the causes of burnout. These are (1) the job-person fit theory, (2) the conservation of resources (COR) theory, (3) the social competence model, and (4) the effort-reward model. Proposed by Maslach and Jackson (1981), the job-person fit theory, suggests that burnout is caused by a mismatch between an individual and their work. The higher the degree of this mismatch, the more severe the burnout experienced by the individual. Hobfoll (1989) proposed the COR theory, which 
is the contemporary mainstream explanation for burnout. COR attempts to understand psychological stress by focusing on the status of a person's resources. Psychological stress is defined as the reaction to the loss of resources, the threat of such a loss, or the failure to gain additional resources after an investment of resources (Hobfoll 2001). In the social competence model proposed by Harrison (1983), burnout is linked to an individual's sense of self-competence. If an individual possesses a strong sense of job competence, his/her motivation to help others tends to increase. However, if the employees fail to achieve the expected goal of helping others, they may develop burnout, which diminishes their motivation to help others. The advantage of this theoretical model is that it focuses on the role and significance of social competence in burnout. Finally, the effort-reward model proposed by Siegrist (1996)--which applies a social exchange theory perspective--asserts that burnout tends to occur when an individual's input exceeds their output.

The harmful consequences of burnout include the followings. First, it generates mental and physical health problems, such as depression, anxiety, distress, and insomnia (Chen and Kao 2012; Cordes and Dougherty 1993; Kristensen et al. 2005; Maslach et al. 2001; Schaufeli et al. 2008; Söderlund 2017). In addition, it facilitates the deterioration of social and familial relationships (Cordes and Dougherty 1993; Maslach et al. 2001; Söderlund 2017). Lastly, it produces dysfunctional outcomes in the individual's relationship with their employer, such as a lower organizational commitment, higher absenteeism, reduced job satisfaction, and an intention to leave (Babakus et al. 1999; Chen and Kao 2012; Cho et al. 2013; Cordes and Dougherty 1993; Deery et al. 2002; Han et al. 2016; Karl and Peluchette 2006; Kristensen et al. 2005; Maslach et al. 2001; Schaufeli et al. 2008; Singh 2000; Singh et al. 1994; Söderlund 2017).

Turnover--which refers to employees leaving an organization--generates a series of company costs and losses. These include the cost of recruitment and training new employees, the reduction of efficiency prior to the employee's departure, and the possible loss of information. Mobley (1977, p.237) proposed that "willingness to leave, which is the tendency of employees to leave," is significant in predicting whether employees will actually leave an organization. Turnover intention is the final stage before employees take the initiative to leave (Zhao and Li 2012). Mobley et al. (1978) argued that turnover intention is an employee's comprehensive manifestation of their dissatisfaction with work, thoughts of quitting, preparation for job-hopping, and their search for other job opportunities. Schaufeli and Bakker (2004) found that burnout mediates the impact of job demands and job resources on turnover intention, while $\mathrm{Gu}$ (2010) concluded that burnout mediates the effect of job demands on turnover intention.

Although many factors affect employees' turnover intention, two factors are paramount to most employees, namely job satisfaction and organizational commitment. Job satisfaction is a reflection of the staff's contentedness toward their job. Thus, a high job satisfaction illustrates that employees possess positive emotions toward their job. The factors governing job satisfaction are work tasks, compensation, promotion, work partners, and superiors. Meanwhile, organizational commitment is an individual's psychological attachment to an organization. This commitment is a psychological contract, which differs from the labor contract signed between the individual and the organization. Through organizational commitment, individuals define the nature and level of their connection with their organization, particularly addressing the content of 
their professional behavior, which is not specified in the formal labor contract. Employees with a higher organizational commitment often have a stronger sense of belonging and identification with the organization.

Turnover intention occurs for many reasons. It is a tendency or desire to escape which is induced within employees and stimulated by factors outside the organization. These stimulants operate based either on employees' dissatisfaction with their current job or organization, or on their yearning for better job opportunities.

Maslach and Leiter (1997) noted that a lack of a sense of fairness in an organization likely leads to burnout. Gabris and Ihrke (2001) studied government employees' perceptions of performance evaluation and the relationship between burnout and job satisfaction, and they pointed out that procedural fairness and distributive justice have predictive effects on burnout.

These studies sufficiently illustrate that burnout acts as a mediator between POS and turnover intention. Therefore, we hypothesize the following:

Hypothesis 1: For frontline employees, burnout mediates the negative relationship between POS and turnover intention.

\section{The moderating role of job resources}

COR theory was originally used to study stress (Benight et al. 1999; Hobfoll et al. 2006), but it is now widely used to study burnout (Buchwald and Hobfoll 2004; Neveu 2007) and challenging work environments (Halbesleben and Bowler 2007; Sun and Pan 2008).

According to the COR theory, the support that an organization can provide reduces the employees' emotional exhaustion and prevents their stress from increasing. Research shows that when employees receive structural support from their organizations, it increases their sense of trust and commitment toward the organization, which consequently reduces the likelihood of job burnout and turnover intention among them (Cuyper et al. 2012). Research also suggests that burnout induces communication, which implies that individuals suffering from burnout may share their symptoms with their colleagues (Bakker and Demerouti 2007). People who experience burnout can negatively affect their colleagues, both by inducing greater personal conflict with colleagues and by disrupting their job tasks. Burnout can thus be "contagious" and perpetuate itself through social interactions (Bakker et al. 2005; González-Morales et al. 2012; Maslach and Leiter 2016). Therefore, organizational support plays an important role in regulating job burnout and turnover intention. Organizational support is different from job resources, as organizational support provides individuals with resources outside the work. Employees' acquisition of appropriate resources accordingly alters their job burnout and turnover intention.

Support from other individuals and/or the organization can reduce the consequences of employee stress (Andrews and Kacmar 2001; Demerouti et al. 2014; Sakurai and Jex 2012). Workplace environments with significant stressors cause high levels of employee burnout, which consequently increases employee turnover (Chiang and Jang 2008).

Job resources refer to the physical, psychological, social, or organizational aspects of a job that can contribute to the achievement of a job goal, reduce the physiological and psychological costs of a job requirement, or promote personal growth and development. Job resources have been extensively studied in the field of human resources. 
However, we find most studies regarding job resources as an independent variable, with few considering job resources as a moderating variable. Organizational support may provide employees with psychological support and recognition, regardless of whether this support could be regulated or even replaced by job resources. Therefore, we propose the following hypothesis:

Hypothesis 2: Job resources moderate the relationship between POS and burnout, such that this relationship is weakened by higher levels of job resources.

\section{Methods}

\section{Sample and data collection}

The study sample consists of the frontline staff that work at the Beijing Petroleum Branch of Sinopec Sales Co., Ltd. The Sinopec Group ranked second in the Fortune Global 500 list in 2019, with its oil business being one of its main revenue channels. The Beijing Petroleum Branch is one of Sinopec's large-scale sales companies. Beijing Petroleum Corp. is the main supply channel for refined oil products in China's capital. The gas station employees receive a joint payment after a salary assessment. The highly repetitive work, standardized division of labor, and mundane quantitative evaluation methods increase the employees' stress and burnout levels. In addition, the job entails high work intensity, low salary, low occupational identity, diverse interests, and a marginal sense of loyalty to the enterprise. As a state-owned enterprise, Beijing Petroleum Corp. also attaches importance to POS through caring for its employees and meeting their needs.

In summary, the research subjects typified those working in state-owned, large-scale, and sales-oriented enterprises. The sample consisted of frontline employees-which included gas station attendants, bookkeepers, and salespeople--who provide retail and wholesale services for both oil and non-oil products. In addition, the company also attaches importance to organizing activities to enhance the staff's POS. To ensure that the survey data reflected the employees' intended meanings as accurately as possible, the survey was conducted onsite using paper questionnaires. From February to June of 2016, a total of 500 questionnaires were distributed and 499 questionnaires were returned, representing a $99.8 \%$ recovery rate. After eliminating the outliers and the questionnaires with missing values, 421 valid questionnaires remained, representing an effective response rate of $84.4 \%$. Table 1 summarizes the respondents' basic information, which includes gender, education, position, and length of service period.

Of the 421 respondents, 245 were men and 176 were women. Among the employees surveyed, 296 were gas station attendants, 65 were salespeople, 26 were bookkeepers, 29 were gas station chiefs, and 5 were managers. Thirty respondents had at most a junior school level education, 273 had a high school or secondary school education, 90 had a college or higher vocational education, and 28 had at least an undergraduate level. Our analysis of the aforementioned statistical results revealed the following:

(1) Men accounted for $58.19 \%$ of the total sample, which was in line with our general perception that men account for a large proportion of gas station frontline staff. 
Table 1 Summary of basic statistical attributes of the sample $(N=421)$

\begin{tabular}{llll}
\hline Attributes & & Number & Proportion \\
\hline Gender & Male & 245 & $58.19 \%$ \\
Education & Female & 176 & $41.81 \%$ \\
& Junior school and below & 30 & $7.13 \%$ \\
& High school and secondary school & 273 & $64.85 \%$ \\
& College and higher vocational school & 90 & $21.38 \%$ \\
Position & Bachelor's degree or above & 28 & $6.65 \%$ \\
& Gas station attendant & 296 & $70.31 \%$ \\
& Salesperson & 65 & $15.44 \%$ \\
& Bookkeeper & 26 & $6.18 \%$ \\
Period & Station chief & 29 & $6.89 \%$ \\
& Manager & 5 & $1.19 \%$ \\
& Less than 1 year & 84 & $19.95 \%$ \\
& 1-2 years & 78 & $18.53 \%$ \\
& 2-3years & 70 & $16.63 \%$ \\
& 3-5years & 71 & $16.86 \%$ \\
& 5-10years & 65 & $15.44 \%$ \\
& More than 10years & 53 & $12.59 \%$ \\
\hline
\end{tabular}

(2) Gas station attendants, salespeople, and bookkeepers accounted for a relatively large proportion of the sample, with gas station attendants representing the highest proportion (70.31\%). This finding is in line with our research purpose.

(3) More than $90 \%$ of the employees had an education level that was lower or commensurate to college education/higher vocational education. Most employees had a high school or secondary school education. This finding indicated that the level of education of frontline employees is generally not high.

(4) The respondents were concentrated in the 20-50 age range. Our data covered all age groups, which ensures the applicability of the results.

\section{Measures}

We measured all of the multi-item variables using a five-point Likert scale, in which 1 represents complete inconsistency and 5 represents full compliance. ${ }^{1}$

\section{Job resources}

Job resources refer to the physical, psychological, social, or organizational aspects of a job that could facilitate the achievement of a job goal, reduce the physiological and psychological costs of a job requirement, or promote personal growth and development. Organizational resources include resources that promote a sense of work control, the achievement of potential qualifications, participation in decision making, and diversification. Meanwhile, social resources refer to support from colleagues, family members, and peers. The measurement of job resources includes four dimensions: training, rewards, regulatory support, and service technical support. A five-point Likert scale was designed for the burnout questionnaire which consisted of 15 questions. The four

${ }^{1}$ Detailed introduction of the questionnaire is available upon request. 
questions that measured the training dimension drew from work by Rogg et al. (2001). The three questions that measured rewards were borrowed from Johnson (1996). Additionally, the four questions that measured regulatory support were selected from the study by Bell et al. (2004). Lastly, the four questions that measured the service technical support were selected from studies by Johnson (1996) and Lytle et al. (1998).

\section{Burnout}

Maslach and Jackson (1981) divided burnout into three dimensions: emotional exhaustion, personality disintegration, and reduced personal accomplishment. Based on the dimensions of emotional exhaustion and personality disintegration, we designed a fivepoint Likert scale containing six questions to assess these two dimensions. These six questions were selected from the burnout scale by Maslach and Jackson (1981).

POS

Based on the literature, this study defined POS as employees' feeling that their organization attaches importance to their job contributions and interests, specifically through supporting their work, identifying their values, and demonstrating concern for their interests. The POS section of the survey questionnaire had a total of six questions which were drawn from the POS measurement tools developed by Eisenberger et al. (1986), and from the research by domestic scholars (Ling et al. 2006) on how to increase support through supportive Party and League practices. A five-point Likert scale was designed for three dimensions related to POS: work support, value identification, and concern for interests.

\section{Turnover intention}

The turnover intention section of the survey questionnaire consisted of four questions which were selected from literature by Babin and Boles (1998), Boshoff and Allen (2000) and Singh et al. (1996). A five-point Likert scale design based on the study of employee absenteeism by Avey et al. (2006) was also used.

\section{Control variables}

This study controlled for the following variables: gender (dummy variable: male and female), age, education (junior school and below; high school and secondary school; college and higher vocational schools; bachelor's degree or above), and the length of service period (less than 1 year; $1-2$ years; $2-3$ years; $3-5$ years; $5-10$ years, and more than 10 years).

\section{Common method variance}

When designing the questionnaire, the dependent and independent variables were separated, and items within each set were intermixed in an effort to reduce single-source method bias (Podsakoff et al. 2003). Prior to administration in the field, the questionnaire was pre-tested with a pilot sample of ten employees, and no changes in the wording of the questions were deemed necessary. The measures of all the perceptual study variables were subjected to an exploratory factor analysis (principal components) with oblique rotation, which suggested that common method bias was not a problem 
Table 2 Reliability test results

\begin{tabular}{lll}
\hline & Cronbach's a & Number of items \\
\hline Job resources (JR) & 0.8063 & 15 \\
Perceived organizational support (POS) & 0.8104 & 6 \\
Burnout (BO) & 0.8799 & 6 \\
Turnover intention (TI) & 0.9310 & 4 \\
\hline
\end{tabular}

(Podsakoff et al. 2003). The measures were also subjected to confirmatory factor analysis and further examined for potential common method variance using Harman's one-factor test (McFarlin and Sweeney 1992). Average item scores were computed for each scale to create composite indicators of the various constructs in the model.

\section{Results}

\section{Construct reliability}

Reliability mainly reflects the stability and consistency of the results when the questionnaire items are repeatedly measured. In empirical research, the most common analysis method for Likert-scale questions is Cronbach's $\alpha$ analysis. The reliability of our survey questions ranged from 0.81 to 0.93 , all of which surpassed the 0.70 benchmark suggested by Nunnally (1978). The results are shown in Table 2 .

\section{Construct validity}

Validity refers to the degree to which a measurement tool or instrument can accurately measure what needs to be measured. There are three types of validity: content validity, criterion validity, and structural validity. Content validity refers to the applicability of the test questions to the sampling of relevant content, that is, the ability of questionnaire to effectively measure the concerned indicators. Most of the questions in this study are based on the results of previous research. Thus, the content validity is satisfactory. Meanwhile, criterion validity refers to whether the data obtained from the scale is meaningful in comparison to the values of other criterion variables. As it is difficult to choose an appropriate criterion in practical research, this study conducted a structural validity analysis. Structural validity refers to the degree of correspondence between the structure and the measured values as reflected in the measurement results.

Table 3 shows that the Kaiser-Meyer-Olkin (KMO) value of job resources is higher than 0.9 and that the KMO values of POS, burnout, and turnover intention are higher than 0.8. The effect of Bartlett's sphericity test was thus significant.

To confirm the discriminant validity of the constructs, we conducted a confirmatory factor analysis. As can be observed in Table 4, all the factors passed the test.

Table 3 Validity analysis results

\begin{tabular}{lll}
\hline & KMO value & Bartlett's sphericity test \\
\hline Job resources (JR) & 0.9015 & 0.000 \\
Perceived organizational support (POS) & 0.8931 & 0.000 \\
Burnout (BO) & 0.8032 & 0.000 \\
Turnover intention (TI) & 0.8579 & 0.000 \\
\hline
\end{tabular}


Table 4 Confirmatory factor analysis

\begin{tabular}{llllll}
\hline Variable & $x^{2}$ & $d f$ & $x^{2} / d f$ & GFI & RMSEA \\
\hline Benchmark & - & - & $<3$ & $>0.9$ & $<0.10$ \\
Result & 384.959 & 210 & 1.833 & 0.926 & 0.044 \\
Variable & $\mathrm{AGFI}$ & $\mathrm{IFI}$ & $\mathrm{RMR}$ & $\mathrm{CFI}$ & $\mathrm{NFI}$ \\
Benchmark & $>0.9$ & $>0.9$ & $<0.05$ & $>0.9$ & $>0.9$ \\
Result & 0.903 & 0.975 & 0.048 & 0.975 & 0.946 \\
\hline
\end{tabular}

\section{Correlations}

For an overall understanding of the sample, we first carried out a correlation analysis of the sample data. Table 5 shows the correlation among the variables. According to the correlation coefficient matrix, there is a significant correlation between the main variables, which provides a good foundation for further analysis.

\section{Hypothesis testing}

The mediating effect is an important phenomenon in the study of the relationships between variables. In our study, burnout is hypothesized as mediating the relationship between POS and turnover intention.

\section{Mediating effects}

The results of the mediation effect are displayed in Table 6. Model 1 represents the first step of the mediation effect: the relationship between POS and turnover intention $(\beta=$ $-0.327, p<0.001)$. Model 2 illustrates the effect of POS on burnout, which is negatively significant $(\beta=-0.322, p<0.001)$. Model 3 shows the third step of the mediation effect. After adding burnout as an independent variable, the relationship between POS and turnover intention significantly decreased $(\beta=-0.161, p<0.01)$. Meanwhile, the relationship between burnout and turnover intention is positive and significant $(\beta=0.515$, $p<0.001)$. All steps were satisfied.

The control variables did not affect the hypothesized relationships, but they showed a significant influence on some model constructs. When considering gender, the results show that burnout is significantly higher in men than in women, which is consistent with our initial deduction. Males may experience greater stress and higher burnout rates due to the nature of their social relationships.

Upon utilizing the bootstrap sampling method to study the mediating effect, the emergent sampling number was 5000. The results in Table 7 show that for the

Table 5 Correlation matrix

\begin{tabular}{lllll}
\hline & $\mathrm{TI}$ & $\mathrm{BO}$ & $\mathrm{POS}$ & $\mathrm{JR}$ \\
\hline Mean & 2.667 & 3.303 & 3.761 & 3.856 \\
S.D. & 1.139 & 1.07 & 0.857 & 0.71 \\
$\mathrm{TI}$ & 1 & & & \\
BO & $0.539^{* *}$ & 1 & 1 & \\
POS & $-0.262^{* *}$ & $-0.272^{* *}$ & $0.598^{* *}$ & 1 \\
$J R$ & $-0.159^{* *}$ & $-0.191^{* *}$ & & \\
\hline
\end{tabular}

Notes. $N=421,{ }^{*} p<0.05,{ }^{* *} p<0.01$ (two-tailed tests); $T I$ Turnover intention, BO Burnout, POS Perceived organizational support, $J R$ Job resources 
Table 6 Results of mediating effects

\begin{tabular}{llll}
\hline & $\begin{array}{l}\text { Turnover intention } \\
\text { Model 1 }\end{array}$ & $\begin{array}{l}\text { Burnout } \\
\text { Model 2 }\end{array}$ & $\begin{array}{l}\text { Turnover intention } \\
\text { Model 3 }\end{array}$ \\
\hline Constant & $3.444\left(11.16^{* * *}\right)$ & $3.674\left(12.63^{* * *}\right)$ & $1.552\left(4.88^{* * *}\right)$ \\
Gender & $-0.414\left(-3.77^{* * *}\right)$ & $-0.381\left(-3.68^{* * *}\right)$ & $-0.218\left(-2.23^{*}\right)$ \\
Age & $-0.014(-1.63)$ & $-0.012(-1.51)$ & $-0.008(-1.03)$ \\
Period & $0.011(0.29)$ & $0.055(1.55)$ & $-0.017(-0.53)$ \\
Education & $-0.091(-1.12)$ & $-0.006(-0.08)$ & $-0.087(-1.23)$ \\
POS & $-0.327\left(-5.32^{* * *}\right)$ & $-0.322\left(-5.55^{* * *}\right)$ & $-0.161\left(-2.89^{* *}\right)$ \\
$B O$ & & & $0.515\left(11.3^{* * *}\right)$ \\
$R^{2}$ & 0.116 & 0.11 & 0.3241 \\
Adjusted $R^{2}$ & 0.105 & 0.099 & 0.3143 \\
$F$ test & $F(5,415)=10.85$ & $F(5,415)=10.26$ & $F(6,414)=33.09$ \\
& $p=0.000^{* * *}$ & $p=0.000^{* * *}$ & $p=0.000^{* * *}$ \\
\hline
\end{tabular}

Notes. $N=421,{ }^{*} p<0.05,{ }^{* *} p<0.01,{ }^{* * *} p<0.001$ (two-tailed tests); $B O$ Burnout, $P O S$ Perceived organizational support

mediating effect of POS on turnover intention, the $95 \%$ interval does not include the number $0(95 \% \mathrm{CI}=[-0.237,-0.102])$. Therefore, it shows that burnout has a mediating effect when POS interacts with turnover intention. POS will first affect burnout, and then turnover intention through burnout. This finding supports Hypothesis 1.

We found that POS significantly and negatively impacts burnout and turnover intention, consistent with traditional ideas. The result shows that burnout among frontline employees is negatively affected by POS. Thus, employees' POS can effectively reduce their turnover intention.

\section{Moderating effects}

To test the moderating effect, we set model regression as the main method of interpretation. In this study, we hypothesized that job resources would moderate the impact of POS on burnout-backed by the belief that job resources can reduce the impact of POS on employees. To examine this effect, we added interaction items to the model and analyzed the interaction term to assess the moderating effect.

The moderating effects were divided into three models. Model 1 included four control variables (gender, age, period, and education) and the independent variable (POS); Model 2 added the moderator variable (job resources) to the basis of Model 1, and Model 3 added the product term of the independent variable and the moderator variable to the basis of Model 2.

Table 7 Results of mediation effect using bootstrapping method

\begin{tabular}{|c|c|c|c|c|c|c|c|}
\hline & Effect & Estimate & SE & $t$ & P & $\mathrm{LLCl}$ & ULCI \\
\hline Direct effect & $\mathrm{POS} \Rightarrow \mathrm{TI}$ & -0.161 & 0.056 & -2.892 & 0.004 & -0.271 & -0.052 \\
\hline \multirow[t]{2}{*}{ Indirect effect process } & $\mathrm{POS} \Rightarrow \mathrm{BO}$ & -0.322 & 0.058 & -5.547 & 0 & -0.436 & -0.208 \\
\hline & $\mathrm{BO} \Rightarrow \mathrm{TI}$ & 0.515 & 0.046 & 11.3 & 0 & 0.426 & 0.604 \\
\hline Total effect & $\mathrm{POS} \Rightarrow \mathrm{TI}$ & -0.327 & 0.062 & -5.316 & 0 & -0.448 & -0.207 \\
\hline Effect & Estimate & Boot SE & BootLLCl & BootULCI & Z & $p$ & \\
\hline $\mathrm{POS} \Rightarrow \mathrm{BO} \Rightarrow \mathrm{TI}$ & -0.166 & 0.034 & -0.237 & -0.102 & -4.915 & 0 & \\
\hline
\end{tabular}

Notes. Results are based on 5000 bootstrap samples. $\mathrm{LLCl}, \mathrm{ULCl}$, BootLLCl, and ULCl are $95 \%$ confidence intervals; $\mathrm{TI}$ Turnover intention, BO Burnout, POS Perceived organizational support 
For Model 1, the purpose was to study the effect of the independent variable (POS) on the dependent variable (burnout), without considering the interference of the moderating variable (job resources). Table 8 shows that the independent variable (POS) is significant $(t=-5.547, p=0.000<0.05)$, meaning that POS has a significant impact on burnout.

The moderating effects can be viewed in two ways. The first is to observe the change in the significance of the $F$-value from Model 2 to Model 3. The second is to observe the significance of the interaction items in Model 3. Table 8 shows that the interaction between POS and job resources was not significant $(t=-0.201$, n.s). This means that when POS affects burnout, the moderating variable (job resources) does not intervene, keeping the influence range of POS consistent.

These results are contrary to our hypothesis. At first, we thought that POS would be moderated or even replaced by job resources. However, in the Chinese context, Party and League supportive practices--a special type of POS--could not be replaced by other job resources.

Frontline employees exhibited lower burnout when POS was high, regardless of the level of job resources by enterprises. Simultaneously, burnout affected employees' turnover intention through an intermediary role. Therefore, improving organizational support can further reduce employees' job burnout and turnover intention.

\section{Discussion}

\section{Conclusion}

Using the data from 421 frontline gas station employees, this study analyzed the relationship between POS, job resources, burnout, and turnover intention, utilizing theoretical and empirical perspectives. We constructed research models and a research framework, developed hypotheses, obtained data through survey questionnaires, and conducted descriptive and regression analyses. Finally, we derived the following conclusions.

Table 8 Results of moderating effects

\begin{tabular}{llll}
\hline & $B O$ & $B O$ & $B O$ \\
& Model 1 & Model 2 & Model 3 \\
\hline Constant & $3.674\left(12.63^{* * *}\right)$ & $3.674\left(12.62^{* * *}\right)$ & $3.680\left(12.56^{* * *}\right)$ \\
Gender & $-0.381\left(-3.68^{* * *}\right)$ & $-0.385\left(-3.71^{* * *}\right)$ & $-0.387\left(-3.70^{* * *}\right)$ \\
Age & $-0.012(-1.51)$ & $-0.012(-1.42)$ & $-0.012(-1.42)$ \\
Period & $0.055(1.55)$ & $0.051(1.42)$ & $0.051(1.42)$ \\
Education & $-0.006(-0.08)$ & $-0.009(-0.11)$ & $-0.009(-0.11)$ \\
POS & $-0.322\left(-5.55^{* * *}\right)$ & $-0.289\left(-3.98^{* *}\right)$ & $-0.291\left(-3.96^{* * *}\right)$ \\
$J R$ & & $-0.066(-0.73)$ & $-0.067(-0.74)$ \\
POSXJR & & $-0.013(-0.201)$ \\
$R^{2}$ & 0.11 & 0.111 & 0.111 \\
Adjusted $R^{2}$ & 0.099 & 0.098 & 0.096 \\
$F$ test & $F(5,415)=10.26$ & $F(6,414)=8.63$ & $F(7,413)=7.38$ \\
& $P=0.000^{* * *}$ & $p=0.000^{* * *}$ & $p=0.000^{* * *}$ \\
\hline
\end{tabular}

Notes. $N=421,{ }^{*} p<0.05,{ }^{* *} p<0.01,{ }^{* * *} p<0.001$ (two-tailed tests); BO Burnout, $P O S$ Perceived organizational support, $J R$ Job resources 
POS plays a key role in improving work performance and reducing job burnout and employee turnover. Employees feel that greater organizational support reduces the negative impact of burnout and turnover intention. Thus, enterprises should provide appropriate organizational support in order to decrease the likelihood of burnout and turnover. This includes expressing their condolences, providing bonuses during holidays, organizing group outings, arranging for group entertainment, and so on.

We examined the mediating effects of burnout on POS and turnover intention. When enterprises provide more organizational support, it reduces their employees' job burnout and turnover intention. Therefore, enterprises should pay attention to their employees' job burnout. Organizational support should be implemented at the right time to effectively increase POS and consequently reduce burnout, turnover intention, and work pressure.

Bakker et al. (2004) found that job resources and demands insignificantly moderate burnout. In contrast, Zellars and Perrewé (2001) found that certain types of social support facilitate the elimination of burnout, while other types are likely to cause it. This study revealed that POS is not moderated by job resources due to the mediating effect of job burnout on turnover intention. Regardless of the degree of support offered by job resources, the direct effect of POS is still strong. Therefore, while improving job resources can often directly reduce employees' burnout and turnover intention, fostering their POS can reduce their feelings of exhaustion. This reduces their turnover intention more effectively.

\section{Theoretical contributions}

This study makes significant theoretical and substantive contributions to research on frontline retail employees in two fundamental ways. First, it provides a new perspective on the impact of POS on burnout and turnover intention. Second, it reveals that the moderating effect of job resources is not significant. Job resources cannot play a moderating role in the relationship between POS and job burnout or turnover intention. This substantiates the necessity of Party and League supportive practices as a form of POS. In addition, we verified the correlation between POS and the traditional theory of job burnout and turnover, thus enriching previous research. The mediation model demonstrates the effect of POS on turnover intention, which not only explicates the role of this support, but also elucidates the circumstances in which POS plays an even greater role.

\section{Practical implications}

Frontline employees act as a liaison between a company and its customers. They are the agents who directly establish the enterprise's image in customers' mind. Therefore, their work performance and service quality are of vital importance to the enterprise. In addition, the productivity of the service industry is directly related to the performance of frontline employees, while work stress and burnout often degrade this performance. Therefore, reducing burnout is an important issue for enterprises. This study reveals that companies can reduce their employees' burnout and turnover intention and optimize their performance and service quality by providing sufficient POS. 
Burnout is a problem not only within enterprises but also for the government, as burnout has become a social phenomenon that has attracted considerable attention. In addition to affecting people's health and an enterprise's goals, service quality, and productivity, excessive work pressure also threatens social stability. Thus, relevant governmental departments should adopt measures to protect employees' rights, interests, and physical and mental health; enhance social harmony; and guarantee the sustainable development of the service industry.

\section{Limitations and future research directions}

The study sample consisted of gas station frontline staff who worked in a distinct environment. It is not certain whether the study's conclusions can be extended to other industries and positions, because we were unable to find relevant data regarding frontline employees in other industries or enterprises. Furthermore, this study tested the model through the employees of a state-owned company. Whether or not the findings are generalizable enough for applying to mixed-ownership firms or private firms requires further research.

In addition, this study only attended to POS as a factor that influences burnout and turnover, excluding the examination of other potential factors such as psychological capital and employee characteristics. Individual psychological values can influence employees' evaluation of resources, which consequently influence their response to stressors (Lamm et al. 2015; Morelli and Cunningham 2012). People with more psychological capital are better equipped to manage stress (Hobfoll 2001). Thus, future studies should introduce other variables exploring these factors in order to enrich this research and yield better recommendations for enterprises and governments.

\section{Acknowledgements \\ Thank Xia Pang (Deputy Secretary of the Party Committee of Fengtai Beijing Petroleum Branch of Sinopec Sales Co., Ltd) for her support in the issuance of questionnaires, information and interviews. Thank Dan Yu and Jinwen Cheng for their help in data analysis. We also need to thank two anonymous reviewers and editor who provide detailed suggestions to the manuscript and let us improve it in order to meet the journal publishing requirement.}

\section{Authors' contributions}

QW designed the study together with CW. Data collection and analysis were done by the authors together. QW drafted the initial manuscript, and the two authors made several rounds of revision together. Both authors read and approved the final manuscript.

Funding

No funding source is available.

\section{Availability of data and materials}

The dataset supporting the conclusions of this article is available upon request.

Competing interests

The authors declare that they have no competing interests.

Received: 10 April 2019 Accepted: 18 February 2020

Published online: 24 March 2020

References

Andrews, M. C., \& Kacmar, K. M. (2001). Discriminating among organizational politics, justice, and support. Journal of Organizational Behavior, 22(4), 347-366.

Avey, J. B., Patera, J. L., \& West, B. J. (2006). The implications of positive psychological capital on employee absenteeism. Journal of Leadership \& Organizational Studies, 13(2), 42-60.

Babakus, E., Cravens, D. W., Johnston, M., \& Moncrief, W. C. (1999). The role of emotional exhaustion in sales force attitude and behavior relationships. Journal of the Academy of Marketing Science, 27(1), 58-70.

Babakus, E., Yavas, U., \& Ashill, N. J. (2009). The role of customer orientation as a moderator of the job demands-burnoutperformance relationship: A surface-level trait perspective. Journal of Retailing, 85(4), 480-492. 
Babin, B. J., \& Boles, J. S. (1998). Employee behavior in a service environment: A model and test of potential differences between men and women. Journal of Marketing, 62(2), 77-91.

Bakker, A. B., Demerouti, E., \& Euwema, M. C. (2005). Job resources buffer the impact of job demands on burnout. Journal of Occupational Health Psychology, 10(2), 170.

Bakker, A. B., Demerouti, E., \& Sanz-Vergel, A. I. (2014). Burnout and work engagement: The JD-R approach. Annual Review of Organizational Psychology and Organizational Behavior, 1(1), 389-411.

Bakker, A. B., \& Demerouti, E. (2007). The job demands-resources model: State of the art. Journal of managerial psychology, 22(3), 309-328.

Bakker, A. B., Demerouti, E., \& Verbeke, W. (2004). Using the job demands-resources model to predict burnout and performance. Human Resources Management, 43(1), 83-104.

Bell, S. J., Mengüç, B., \& Stefani, S. L. (2004). When customers disappoint: A model of relational internal marketing and customer complaints. Journal of the Academy of Marketing Science, 32(2), 112-126.

Benight, C. C., Ironson, G., Klebe, K., Carver, C. S., Wynings, C., Burnett, K., \& Schneiderman, N. (1999). Conservation of resources and coping self-efficacy predicting distress following a natural disaster: A causal model analysis where the environment meets the mind. Anxiety, stress and coping, 12(2), 107-126.

Boshoff, C., \& Allen, J. (2000). The influence of selected antecedents on frontline staff's perceptions of service recovery performance. International Journal of Service Industry Management, 11(1), 63-90.

Buchwald, P., \& Hobfoll, S. E. (2004). Burnout aus ressourcentheoretischer Perspektive. Psychologie in Erziehung und Unterricht, $51(4), 247-257$.

Chen, C. F., \& Kao, Y. (2012). Investigating the antecedents and consequences of burnout and isolation among flight attendants. Tourism Management, 33(4), 868-874.

Cheng, J. C., \& Yi, O. (2018). Hotel employee job crafting, burnout, and satisfaction: The moderating role of perceived organizational support. International Journal of Hospitality Management, 72, 78-85.

Cherniss, C., \& Cherniss, C. (1980). Staff burnout: Job stress in the human services. Beverly Hills: Sage Publications.

Chiang, C. F., \& Jang, S. S. (2008). An expectancy theory model for hotel employee motivation. International Journal of Hospitality Management, 27(2), 313-322.

Cho, Y. N., Rutherford, B. N., \& Park, J. K. (2013). Emotional labor's impact in a retail environment. Journal of Business Research, $66(11), 2338-2345$

Cohen, S., \& Wills, T. A. (1985). Stress, social support, and the buffering hypothesis. Psychological Bulletin, 98(2), 310-357.

Cordes, C. L., \& Dougherty, T. W. (1993). A review and an integration of research on job burnout. Academy of Management Review, 18(4), 621-656.

Cropanzano, R., Howes, J. C., Grandey, A. A., \& Toth, P. (1997). The relationship of organizational politics and support to work behaviors, attitudes, and stress. Journal of Organizational Behavior, 18(2), 159-180.

Cuyper, N. D., Mäkikangas, A., Kinnunen, U., \& Witte, H. D. (2012). Cross-lagged associations between perceived external employability, job insecurity, and exhaustion: Testing gain and loss spirals according to the conservation of resources theory. Journal of Organizational Behavior, 33(6), 770-788.

Day, D. V.. \& Bedeian, A. G. (1991). Predicting job performance across organizations: The interaction of work orientation and psychological climate. Journal of Management, 17(3), 589-600.

Deery, S., Iverson, R., \& Walsh, J. (2002). Work relationships in telephone call centres: Understanding emotional exhaustion and employee withdrawal. Journal of Management Studies, 39(4), 471-496.

Demerouti, E., Bakker, A. B., \& Leiter, M. (2014). Burnout and job performance: The moderating role of selection, optimization, and compensation strategies. Journal of occupational health psychology, 19(1), 96.

Dong, Z. Q., \& Wei, X. H. (2018). The active role of party organizations in private enterprises: An empirical study on the protection of workers' rights and interests. Economic Perspectives, 1, 14-26.

Eisenberger, R., Huntington, R., Hutchison, S., \& Sowa, D. (1986). Perceived organizational support. Journal of Applied Psychology, 71(3), 500-507.

Fogarty, T. J., Singh, J., Rhoads, G. K., \& Moore, R. K. (2000). Antecedents and consequences of burnout in accounting: Beyond the role stress model. Behavioral Research in Accounting, 12, 31-68.

Gabris, G. T., \& Ihrke, D. M. (2001). Does performance appraisal contribute to heightened levels of employee burnout? The results of one study. Public Personnel Management, 30(2), 157-172.

González-Morales, M. G., Peiró, J. M., Rodríguez, l., \& Bliese, P. D. (2012). Perceived collective burnout: A multilevel explanation of burnout. Anxiety, Stress \& Coping, 25(1), 43-61.

Gu, Y. D. (2010). A research about the impact of job stress and burnout on turnover intention: Based on the Maslach burnout model. Economic Management Journal, 10(32), 80-82.

Halbesleben, J. R., \& Bowler, W. M. (2007). Emotional exhaustion and job performance: the mediating role of motivation. Journal of applied psychology, 92(1), 93.

Han, S. J., Bonn, M. A., \& Cho, M. (2016). The relationship between customer incivility, restaurant frontline service employee burnout and turnover intentions. International Journal of Hospitality Management, 52, 97-106.

Harrison, W. D. (1983). A social competence model of burnout. In B. A. Farber (Ed.), Stress and burnout in the human services professions (pp. 29-39). New York: Pergamon Press.

Hobfoll, S. E. (1989). Conservation of resources: A new attempt at conceptualizing stress. American Psychologist, 44(3), 513-524.

Hobfoll, S. E. (2001). The influence of culture, community, and the nested-self in the stress process: Advancing conservation of resources theory. Applied Psychology, 50(3), 337-421.

Hobfoll, S. E., Tracy, M., \& Galea, S. (2006). The impact of resource loss and traumatic growth on probable PTSD and depression following terrorist attacks. Journal of Traumatic Stress: Official Publication of the International Society for Traumatic Stress Studies, 19(6), 867-878.

Johnson, J. W. (1996). Linking employee perceptions of service climate to customer satisfaction. Personnel Psychology, 49(4), 831-851.

Karl, K., \& Peluchette, J. (2006). How does workplace fun impact employee perceptions of customer service quality? Journal of Leadership \& Organizational Studies, 13(2), 2-13.

Kristensen, T. S., Borritz, M., Villadsen, E., \& Christensen, K. B. (2005). The Copenhagen burnout inventory: A new tool for the assessment of burnout. Work \& Stress, 19(3), 192-207. 
Lamm, E., Tosti-Kharas, J., \& King, C. E. (2015). Empowering employee sustainability: Perceived organizational support toward the environment. Journal of Business Ethics, 128(1), 207-220.

Ling, W. Q., Yang, H. J., \& Fang, L. L. (2006). Perceived organizational support (POS) of the employees. Acta Psychologica Sinica, 38(2), 281 289.

Lytle, R. S., Hom, P. W., \& Mokwa, M. P. (1998). SERV*OR: A managerial measure of organizational senvice-orientation. Journal of Retailing, 74(4), 455-489.

Maslach, C., \& Jackson, S. E. (1981). The measurement of experienced burnout. Journal of Organizational Behavior, 2(2), 99-113.

Maslach, C., \& Leiter, M. P. (1997). The truth about burnout: How organizations cause personal stress and what to do about it. San Francisco: Jossey-Bass.

Maslach, C., \& Leiter, M. P. (2016). Understanding the burnout experience: Recent research and its implications for psychiatry. World Psychiatry, 15(2), 103-111.

Maslach, C., Schaufeli, W. B., \& Leiter, M. P. (2001). Job burnout. Annual Review of Psychology, 52(1), 397-422.

McFarlin, D. B., \& Sweeney, P. D. (1992). Distributive and procedural justice as predictors of satisfaction with personal and organizational outcomes. Academy of Management Journal, 35(3), 626-637.

McMillin, R. (1997). Customer satisfaction and organizational support for senvice providers. Florida: Doctoral dissertation, University of Florida.

Meyer, J. P., Allen, N. J., \& Smith, C. A. (1993). Commitment to organizations and occupations: Extension and test of a threecomponent conceptualization. Journal of Applied Psychology, 78(4), 538.

Mobley, W. H. (1977). Intermediate linkages in the relationship between job satisfaction and employee turnover. Journal of Applied Psychology, 62(2), 237.

Mobley, W. H., Horner, S. O., \& Hollingsworth, A. T. (1978). An evaluation of precursors of hospital employee turnover. Journal of Applied Psychology, 63(4), 408-414.

Morelli, N. A., \& Cunningham, C. J. (2012). Not all resources are created equal: COR theory, values, and stress. The Journal of Psychology, 146(4), 393-415.

Neveu, J. P. (2007). Jailed resources: Conservation of resources theory as applied to burnout among prison guards. Journal of Organizational Behavior: The International Journal of Industrial, Occupational and Organizational Psychology and Behavior, 28(1), 21-42.

Nunnally, J. C. (1978). Psychometric theory (2nd ed.). New York: McGraw-Hill.

Palmer, J. C., Komarraju, M., Carter, M. Z., \& Karau, S. J. (2017). Angel on one shoulder: Can perceived organizational support moderate the relationship between the dark triad traits and counterproductive work behavior? Personality and Individual Differences, 110, 31-37.

Pienaar, J., \& Willemse, S. A. (2008). Burnout, engagement, coping and general health of service employees in the hospitality industry. Tourism Management, 29(6), 1053-1063.

Podsakoff, N. P., LePine, J. A., \& LePine, M. A. (2007). Differential challenge stressor-hindrance stressor relationships with job attitudes, turnover intentions, turnover, and withdrawal behavior: A meta-analysis. Journal of Applied Psychology, 92(2), 438-454.

Podsakoff, P. M., MacKenzie, S. B., Lee, J. Y., \& Podsakoff, N. P. (2003). Common method biases in behavioral research: A critical review of the literature and recommended remedies. Journal of Applied Psychology, 88(5), 879-903.

Rogg, K. L., Schmidt, D. B., Shull, C., \& Schmitt, N. (2001). Human resource practices, organizational climate, and customer satisfaction. Journal of Management, 27(4), 431-449.

Sakurai, K., \& Jex, S. M. (2012). Coworker incivility and incivility targets' work effort and counterproductive work behaviors: The moderating role of supervisor social support. Journal of Occupational Health Psychology, 17(2), 150-161.

Schaufeli, W. B., \& Bakker, A. B. (2004). Job demands, job resources, and their relationship with burnout and engagement: A multi-sample study. Journal of Organizational Behavior, 25(3), 293-315.

Schaufeli, W. B., Taris, T. W., \& Van Rhenen, W. (2008). Workaholism, burnout, and work engagement: Three of a kind or three different kinds of employee well-being? Journal of Applied Psychology, 57(2), 173-203.

Siegrist, J. (1996). Adverse health effects of high-effort/low-reward conditions. Journal of Occupational Health Psychology, 1(1), $27-41$.

Singh, J., Goolsby, J. R., \& Rhoads, G. K. (1994). Behavioral and psychological consequences of boundary spanning burnout for customer service representatives. Journal of Marketing Research, 31(4), 558-569.

Singh, J. (2000). Performance productivity and quality of frontline employees in service organizations. Journal of Marketing, 64(2), 15-34.

Singh, J., Verbeke, W., \& Rhoads, G. K. (1996). Do organizational practices matter in role stress processes? A study of direct and moderating effects for marketing-oriented boundary spanners. Journal of Marketing, 60(3), 69-86.

Söderlund, M. (2017). Employee display of burnout in the service encounter and its impact on customer satisfaction. Journal of Retailing \& Consumer Services, 37, 168-176.

Sun, L. Y., \& Pan, W. (2008). HR practices perceptions, emotional exhaustion, and work outcomes: A conservation-of-resources theory in the Chinese context. Human Resource Development Quarterly, 19(1), 55-74.

Tian, Q.. Zhang, L., \& Zou, W. (2014). Job insecurity and counterproductive behavior of casino dealers-The mediating role of affective commitment and moderating role of supervisor support. International Journal of Hospitality Management, 40, $29-36$.

Wang, G., Liu, D., \& Wang, X. (2011). Effects of perceived organizational support and guanxi on salesperson performance: The mediation of customer need knowledge. Frontiers of Business Research in China, 5(3), 422-435.

Xu, X. F., Che, H. S., Lin, X. H., \& Zhang, J. M. (2005). About the organizational support theory. Psychological Science, 34(1), 130-132.

Yagil, D. (2006). The relationship of service provider power motivation, empowerment and burnout to customer satisfaction. International Journal of Service Industry Management, 17(3), 258-270.

Zellars, K. L., \& Perrewé, P. L. (2001). Affective personality and the content of emotional social support: Coping in organizations. Journal of Applied Psychology, 86(3), 459-467.

Zhao, Y. S., \& Li, M. (2012). The research on the relationship between the job burnout and turnover intention of post 80s knowledge workers in business-Perceived organizational support as moderator. Shanghai Management Science, 34(3), 75-79.

\section{Publisher's Note}

Springer Nature remains neutral with regard to jurisdictional claims in published maps and institutional affiliations. 